\title{
A RANDOMIZED CLINICAL TRIAL TO COMPARE SMALL FREQUENT BOLUSES TECHNIQUE WITH THAT OF TRADITIONAL INTERMITTENT TOP-UPS AND CONTINUOUS EPIDURAL INFUSION, FOR MAINTENANCE OF EPIDURAL LABOUR ANALGESIA
}

\author{
Ramchandra Vinayak Shidhaye ${ }^{1}$, Vaijayanti Badhe ${ }^{2}$, Devdas Divekar ${ }^{3}$, Vitthal Dhulkhed $^{4}$, Pravin \\ Thorat $^{5}$, Rahul Shidhaye ${ }^{6}$ \\ ${ }^{1}$ M.D. D.A. Professor, ${ }^{2}$ M.D. D.A. Professor, ${ }^{3}$ M.D. D.A. Professor, ${ }^{4}$ M.D. D.A. Professor, \\ M.B.B.S. D.A. Assistant Lecturer, Department of Anesthesiology and Critical Care, Pravara Institute of \\ Medical Sciences, Loni 413736 INDIA, ${ }^{6}$ M.D. M.H.S. Lecturer, Indian Institute of Public Health (IIPH), \\ Hyderabad, India.
}

*Corresponding Author: rvshidhaye@gmail.com

Key words: epidural analgesia, labour, intermittent, top ups, infusion

\begin{abstract}
Background
Prospective randomized study was designed to compare the safety and efficacy of administering small, frequent boluses of Bupivacaine and Fentanyl mixture epidurally for labour analgesia maintenance, with that of continuous infusion and traditional intermittent boluses.
\end{abstract}

\begin{abstract}
Methods
Sixty patients having full term uncomplicated pregnancies in active labour were selected randomly after ethics committee approval. Initial block was established by injecting loading dose of $10 \mathrm{ml}$ of Bupivacaine $0.125 \%$ with Fentanyl $(2 \mu \mathrm{g} / \mathrm{ml})$ mixture epidurally and maintained by $3 \mathrm{ml}$ at 15 minutes interval (SFB), or $10 \mathrm{ml}$ hourly as bolus (TIT) or continuous infusion $10 \mathrm{ml} / \mathrm{hr}$ (CEI). Analgesia quality, VAS, level of overall satisfaction, duration of labour, and total dose required were compared.
\end{abstract}

Results

Overall quality of analgesia was very good in all techniques. Difference in cumulative analgesia score percentage for 0 (No pain, pressure or tightening) was significant. Average VAS was $0.9 \pm 0.87$ in SFB $2.55 \pm 0.91$ in TIT and $0.4 \pm 0.79$ in CEI Group. $30 \%$ of patients from SFB $5 \%$ from TIT and $50 \%$ from CEI expressed the analgesia as excellent. Total dose required and duration of labour was similar in all groups.

\section{Conclusions}

Our study revealed that the technique of small frequent boluses at fifteen min intervals is superior to the technique of traditional intermittent top-ups but not to the technique of continuous epidural infusion as regards quality of analgesia. Nevertheless it can be a better alternative for maintenance of epidural labour analgesia in hospitals with limited resources.

Epidural labour analgesia has not been fully accepted and is not routinely practised in many centres in developing countries ${ }^{1}$. Most important reasons are scarcity of qualified anaesthesiologists, and budgetary constraints. Patient load always outweighs resources in developing countries and many centres still lack sophisticated equipment, such as infusion pumps and devices for patient - controlled epidural analgesia (PCEA). Researchers are currently investigating the technique of regularly scheduled (programmed) automated intermittent boluses to improve analgesia ${ }^{2}$. Small, frequent boluses (SFB) can be delivered manually, avoiding the need for special devices. This simple modification would overcome the shortcomings in the working conditions of developing countries. 
The same midwife attending the parturient during labour can be easily trained for administering the boluses once an anaesthesiologist has introduced an epidural catheter and established a block initially. Our study was designed to compare the safety and efficacy of epidurally, manually administered SFBs at fifteen minute intervals of a mixture of bupivacaine and fentanyl for maintenance of labour analgesia with CEI and traditional, intermittent boluses of the same drugs.

\section{Materials \& Methods}

After approval from the hospital ethics committee, the study was carried out in randomly selected sixty uncomplicated full term pregnant patients who were in active labour. Exclusion criteria were multiple-pregnancy or abnormal presentation, systemic disorder like diabetes mellitus, hypertension and heart disease, spine deformity, blood coagulation disorder, bad obstetric history and foetal abnormity.

Written, informed and valid consent, was obtained from pregnant mothers. Five hundred millilitres of Ringer's lactate was administered intravenously as a preload and labour analgesia commenced during the first stage of labour when cervical dilatation was 3 to $4 \mathrm{~cm}$, through an epidural catheter inserted under aseptic conditions at L2 - L3 or L3 L4 space through a 16 G Tuohy needle. Epidural space was identified through the loss-of-resistance technique. The catheter was placed cephalad two spaces $(3$ to $4 \mathrm{~cm})$ above the point of insertion. Its position was confirmed by administering a test dose of $3 \mathrm{ml}$ of lignocaine (2\%) with adrenaline. A loading-dose mixture of $10 \mathrm{ml}$ of bupivacaine $(0.125 \%)$ and fentanyl $(2 \mu \mathrm{g} / \mathrm{ml})$ was administered epidurally targeting initial sensory block to $\mathrm{T} 10$ level. Additional doses of bupivacaine were administered if required. The patients were then allocated randomly for the maintenance of analgesia by one of the three techniques:

- Group I: SFB technique: Three millilitres of mixture of bupivacaine $(0.125 \%)$ with fentanyl $(2 \mu \mathrm{g} / \mathrm{ml})$ injected through epidural catheter every 15 minutes.

- Group II: Traditional intermittent top-up (TIT) technique: Ten millilitres of mixture of bupivacaine $(0.125 \%)$ with fentanyl $(2 \mu \mathrm{g} / \mathrm{ml})$ injected through epidural catheter hourly.
- Group III: CEI technique: A continuous infusion of mixture of bupivacaine $(0.125 \%)$ with fentanyl $(2 \mu \mathrm{g} / \mathrm{ml})$ by infusion pump at the rate of $10 \mathrm{ml} / \mathrm{hr}$ through the epidural catheter.

Randomization was carried out based on blocking. Blocks of size 3 with treatment allocation of 1:1:1 for group I, group II and group III were created. A block of 3 patients was assigned to one of the blocks created.

The level of sensory blockade was tested by a pinprick method in midline and motor blockade was tested with the modified Bromage scale.

When the sensory block was higher than T7 or the motor blockade was below score 4 as per the Bromage scale one SFB dose was omitted in the first group, infusion was stopped for 10 minutes in the CEI group and top-up was delayed for 10 minutes in the TIT group patients. The patients were reassessed after 10 minutes and the action was repeated.

When patients had severe break through pain (VAS pain score $>3$ ) additional top-ups of $3 \mathrm{ml}$ of $0.125 \%$ bupivacaine with fentanyl 2 micrograms / $\mathrm{ml}$ were administered.

Maternal parameters like pulse rate, blood pressure and respiratory rate were monitored frequently. Foetal heart rate (FHR) was monitored through tococardiography. Bearing-down ability was assessed by asking the patients about the perception of the urge to bear down. Neonates were assessed by Apgar score at 1 minute and 5 minutes intervals after birth. The patients were observed for any side effects or complications, such as pruritus, nausea and vomiting, hypotension, headache, sedation and respiratory depression. Labour analgesic drug administration was stopped after delivery and the duration of labour analgesia was recorded. The total dose of bupivacaine and fentanyl was also calculated. The quality of analgesia was assessed hourly. The patients were asked about pain relief during the last hour and were given scores as follows:

- $0=$ No pain, pressure or tightening sensation

- 1 = Awareness of pressure or tightening sensation but not painful 
- 2 = Slight pain or pressure sensation but not distressing

- $3=$ Distressing pain or pressure sensation

Even when the patients scored higher for a very short period, the higher score was recorded for that hour. All the patients were interviewed within 24 hours of delivery by an anaesthetist colleague who was unaware of the technique used and recorded a linear visual analogue scale (VAS) pain score on the patient's opinion about overall efficacy of analgesia. On this scale, $0 \mathrm{~cm}$ indicated no pain and $10 \mathrm{~cm}$ indicated worst pain. They were also asked about the level of their satisfaction regarding the quality of analgesia, which was graded as 'excellent', 'good' or 'bad'.

The analysis of variance, the Kruskal-Wallis test and the chi-square test were applied where appropriate. $\mathrm{P}<0.05$ was considered significant. For clarity, a proportion of the results were expressed as a percentage but statistical calculations were performed on actual numbers.

\section{Results}

The patients' physical characteristics are shown in Table I. There was no significant difference with respect to age, height, weight and parity in the three groups ( $p$-value $>0.05$ ).

Table I: Baseline characteristics

\begin{tabular}{|l|l|l|l|}
\hline Characteristics & SFB Group & TIT Group & CEI Group \\
\cline { 2 - 4 } & Mean \pm SD & Mean \pm SD & Mean \pm SD \\
\hline Age in years & $24.85 \pm 2.67$ & $24.2 \pm 2.26$ & $23.85 \pm 2.84$ \\
\hline Height in cms. & $153.15 \pm 5.8$ & $152.25 \pm 5.7$ & $154.65 \pm 5.6$ \\
\hline Weight in kg & $48.35 \pm 5.1$ & $50.80 \pm 4.6$ & $50.75 \pm 2.7$ \\
\hline Primipara & $10(50 \%)$ & $12(60 \%)$ & $11(55 \%)$ \\
\hline Secondpara & $07(35 \%)$ & $06(30 \%)$ & $05(25 \%)$ \\
\hline Multipara & $03(15 \%)$ & $02(10 \%)$ & $04(20 \%)$ \\
\hline
\end{tabular}

p-value $>0.05$

Table II comparing the quality of analgesia in the three groups shows in $54(65 \%)$ observations patients were totally pain free in SFB group, 41 $(45 \%)$ in TIT group and $75(85 \%)$ in CEI group. This difference is significant $(\mathrm{p}<0.01)$.

Only one patient in the SFB group reported distressing pain, while none in CEI group had distressing pain. The patients complaining of mild pain or a pressure sensation were $8(10 \%)$ observations in the SFB group, $27(30 \%)$ in the TIT group and $4(5 \%)$ in the CEI group. This difference is also significant ( $p$-value $<0.01)$.

Table II: Quality of analgesia (expressed as percentage of all hourly observations for each

\begin{tabular}{|c|c|c|c|}
\hline $\begin{array}{l}\text { Cumulative } \\
\text { analgesia score } \\
\text { in } \%\end{array}$ & SFB Group & TIT Group & CEI Group \\
\hline 0 & $54(65 \%)$ & $41(45 \%)^{* *}$ & $75(85 \%)^{* *}$ \\
\hline 1 & $16(20 \%)$ & $9(10 \%)^{*}$ & $9(10 \%)^{*}$ \\
\hline 2 & $8(10 \%)$ & $27(30 \%)^{* *}$ & $4(5 \%)$ \\
\hline 3 & $4(5 \%)$ & $14(15 \%)^{*}$ & 0 \\
\hline $\begin{array}{l}\text { Total hourly } \\
\text { assessments }\end{array}$ & 82 & 91 & 88 \\
\hline
\end{tabular}

score in all techniques)

Statistical analysis was carried out with Stata 10.

\section{*p-value significant at $0.05 ; \quad * *$ p-value significant at 0.01}

\section{Group I (the SFB group) is taken as the reference group.}

Table III compares the overall maternal satisfaction in respect of the quality of analgesia given during the post-delivery interviews by all the groups. The overall impression of the quality of analgesia was indicated as excellent by $30 \%$ of the patients from the SFB group, by $5 \%$ from the TIT group and by $50 \%$ from the CEI group. This difference is significant ( $p$-value $<0.01$ ). The average VAS score was highest in TITs $(2.55 \pm$ $0.91)$, lowest in CEI $(0.4 \pm 0.79)$ and intermediate in SFBs $(0.9 \pm 0.87)$. This difference between SFBs and TITs and between SFBs and CEI is also significant. (p-value $<0.01$ ). 
Table III: Maternal satisfaction: Overall impression of quality of analgesia indicated in post-delivery interviews in all three groups

\begin{tabular}{|c|c|c|c|}
\hline & SFB Group & $\begin{array}{l}\text { TIT } \\
\text { Group }\end{array}$ & CEI Group \\
\hline $\begin{array}{l}\text { No. of mothers indicating } \\
\text { level of overall } \\
\text { satisfaction as excellent }\end{array}$ & $6(30 \%)^{\star *}$ & $1(5 \%)^{* *}$ & $10(50 \%)$ \\
\hline $\begin{array}{l}\text { Level of analgesia (VAS } \\
\text { score) } \\
\text { Mean } \pm \text { SD }\end{array}$ & $0.9 \pm 0.87^{* *}$ & $\begin{array}{l}2.55 \pm \\
0.91^{* \star}\end{array}$ & $0.4 \pm 0.79$ \\
\hline $\begin{array}{l}\text { Total no. of delivered } \\
\text { mothers }\end{array}$ & 20 & 20 & 20 \\
\hline
\end{tabular}

\section{*p-value significant at $0.05 ; \quad * *$ p-value significant at 0.01}

\section{Group I (the SFB group) is taken as the reference group.}

Comparing other outcome characteristics of the three groups showed no significant difference in the total dose requirements or duration of labour analgesia. Only one patient from the CEI group required a Caesarean section. Two patients from TIT group and one patient from the SFB group were delivered vaginally with assisted outlet forceps due to obstetrical reasons.

Average pulse rate and average blood pressure showed a significant rise in the TIT group compared with the other two groups (p-value < 0.05). The Apgar score was comparable in all three groups. FHR remained stable (range 100-160 beats/minute) in all patients of three groups throughout, which was comparable. No patient experienced any other major side effects during the procedure.

Table IV: Comparison of other outcome characteristics in all three groups

\begin{tabular}{|l|l|l|l|}
\hline Characteristics & SFB Group & TIT Group & CEI Group \\
\cline { 2 - 4 } & Mean \pm SD & Mean \pm SD & Mean \pm SD \\
\hline $\begin{array}{l}\text { Total dose required } \\
(\mathrm{ml})\end{array}$ & $40.55 \pm 8.53$ & $44.75 \pm 8.66$ & $43.5 \pm 8.29$ \\
\hline $\begin{array}{l}\text { Duration of labour } \\
\text { analgesia (hrs) }\end{array}$ & $4.1 \pm 0.88$ & $4.55 \pm 0.87$ & $4.4 \pm 0.86$ \\
\hline Apgar score & $8.5 \pm 0.87$ & $8.8 \pm 0.87$ & $8.75 \pm 0.17$ \\
\hline
\end{tabular}

\begin{tabular}{|l|l|l|l|}
\hline Characteristics & SFB Group & TIT Group & CEI Group \\
\hline $\begin{array}{l}\text { Average pulse } \\
\text { rate/min. }\end{array}$ & $80.15 \pm 2.80$ & $83.1 \pm 2.72^{\star}$ & $79.95 \pm 2.65$ \\
\hline $\begin{array}{l}\text { Average blood } \\
\text { pressure (mm of Hg) }\end{array}$ & $108.1 \pm 2.57$ & $110.7 \pm 4.57^{\star}$ & $108.4 \pm 4.32$ \\
\hline $\begin{array}{l}\text { No. of occasions FHR } \\
\text { <100/min. }\end{array}$ & 0 & 0 & 0 \\
\hline $\begin{array}{l}\text { No. of occasions FHR } \\
>160 / \text { min. }\end{array}$ & 0 & 0 & 0 \\
\hline
\end{tabular}

\section{*p-value significant at $0.05 ; \quad * *$ p-value significant at 0.01}

\section{Group I (the SFB group) is taken as the reference group.}

\section{Discussion}

Research for the ideal technique of maintaining epidural analgesia after the initial-level block is ongoing. Continuous infusion techniques ${ }^{4,5}$, use of more dilute solutions ${ }^{6,7}, \mathrm{PCEA}^{8-16}$, and different techniques of PCEA like background dosing, none ${ }^{17}$, fixed infusion as background, variable infusion (computer-integrated) ${ }^{18}$, programmed intermittent boluses (PIEBs) and automated mandatory boluses ${ }^{2,19,20}$, have been used. Automated systems designed to administer a small bolus dose of anaesthetic at programmable intervals may combine the advantages of both manual bolus and continuous epidural infusion (CEI) systems.

Wong et al ${ }^{2}$ compared a PIEB (6 $\mathrm{ml}$ of bolus every 30 minutes) with CEI with the assumption that small frequent boluses may avoid wide fluctuations in sensory levels, commonly seen with traditional manually administered intermittent boluses and at the same time reduce the total anaesthetic dose as in CEI. For sake of simplicity and economy we used $3 \mathrm{ml}$ bolus at 15-minute intervals manually instead of using automated systems. We hypothesised that the small, frequent top-up technique would be an acceptable alternative to CEI in respect of the quality of analgesia, overall maternal satisfaction and safety and would be preferable to the traditional large, intermittent top-ups. We have used a mixture of $0.125 \%$ of bupivacaine and $2 \mu \mathrm{g} / \mathrm{ml}$ of fentanyl for all three epidural analgesia techniques, as $0.125 \%$ 
has been found to be the ideal concentration ${ }^{6}$. Fentanyl was added because a combination of an opioid with local anaesthetic reduces the local anaesthetic requirement, hastens the onset of action and provides intense analgesia without affecting bearing-down ability. ${ }^{21}$

Our results differ from the study outcomes of Wong et $\mathrm{al}^{2}$ and Chua and Sia ${ }^{22,}$ who found equivalent analgesia between PIEBs (which may be equated to SFBs) and CEI and patient satisfaction higher in PIEBs than CEI, while we found the CEI group superior. Our findings are similar to the studies by Lamont RF et al ${ }^{4}$ and Virmani et al ${ }^{5}$ but differ from those by Fettes et al ${ }^{23}$ when TIT and CEI are compared. Fettes et al ${ }^{23}$ showed TIT to be a more efficacious mode of analgesia than $\mathrm{CEI}$, as it requires fewer supplementary injections and fewer drugs to maintain similar pain scores, sensory levels and motor blockade compared with the continuous group.

Our study revealed that the technique of SFBs is superior to the technique of traditional intermittent boluses but not to the technique of CEI as regards the quality of analgesia.

The total dose requirement of the drug was similar in all three groups. In our study motor blockade necessitating obstetric interventions was similar to the findings of Usha Kiran et $\mathrm{al}^{7}$ who found that reduction in motor blockade associated with intermittent top-up epidural regimes compared with CEI, did not affect the outcome of labour.

All the patients were haemodynamically stable, although average pulse rate and blood pressure showed significant increase in the TIT group compared with the other two groups. This indicates the quality of analgesia to be lower in TIT, causing increased tachycardia and hypertension. There was not a single incidence of foetal distress and the Apgar score was similar in all the groups. No patient experienced any other major side effect during the procedure.

In conclusion, our study revealed that the technique of SFBs at 15-minute intervals is superior to TIT technique but not to CEI technique in respect of quality of analgesia. It is nevertheless an acceptable alternative to CEI from the point of maternal satisfaction. This technique is definitely a good method of maintenance of epidural labour analgesia in hospitals where CEI technique is not possible due to scarcity of infusion pumps. A midwife attending the parturient may be trained to administer maintenance top-ups once an anaesthesiologist has introduced an epidural catheter and established a block initially.

\section{References}

1. Hug I, Chattopadhyay C, Mitra GR, Kar Mahapatra RM, Schneider MC. Maternal expectations and birth-related experiences: A survey of pregnant women of mixed parity from Calcutta, India. Int $\mathrm{J}$ Obstet Anaesth. 2008 ; 17:112-7.

2. Wong CA, Ratliff JT, Sullivan JT, Scavone BM, etel. A randomized comparison of programmed intermittent epidural bolus with continuous epidural infusion for labour analgesia. Anaesth Analg. 2006;102:904-909.

3. Breen TW, Shapiro T, Glass B, Foster-Payne D, Oriol NE. Epidural anesthesia for labor in an ambulatory patient. Anesth Analg. 1993; 77:91924.

4. Lamont RF, Pinney D, Rodgers P, Bryant TN. continuous versus intermittent epidural analgesia: A randomised trial to observe obstetric outcome. Anesthesia. 1989;44:893-896.

5. Virmani R, Ghai A, Singh DK. A study to compare continuous epidural infusion and intermittent bolus of bupivacaine for postoperative analgesia following renal surgery. Southern African Journal of Anaesthesia and Analgesia. 2008;14:19-22.

6. Harms C, Siegemund M, Marsch SC, Surbek DV, Hösli I, Schneider MC. Initiating extradural analgesia during labour: comparison of three different bupivacaine concentrations used as the loading dose. Fetal Diagn Ther.1999 ; 14(6):36874.

7. Usha Kiran TS, Thakur MB, Bethel JA, Bhal PS, Collis RE. Comparison of continuous infusion versus midwife administered top-ups of epidural bupivacaine for labour analgesia: Effect on second stage of labour and mode of delivery. Int J Obstet Anesth. 2003;12:9-11.

8. Purdie J, Reid J, Thorburn J, Asbury AJ. Continuous extradural analgesia: Comparison of midwife top-ups, continuous infusions and patient controlled administration. $\mathrm{Br} \mathrm{J}$ Anaesth. 1992;68:580-584.

9. Paech MJ. Patient-controlled epidural analgesia in obstetrics. Int J Obstet Anesth. 1996;5:115-125.

10. Van der Vyver M, Halpern S, Joseph G. Patientcontrolled epidural analgesia versus continuous 
infusion for labour analgesia: A meta-analysis. Br J Anaesth. 2002;89:459-465.

11. Ferrante FM, Lu L, Jamison SB, Datta S. Patientcontrolled epidural analgesia: Demand dosing. Anaesth Analg. 1991;73:547-552.

12. Tan S, Reid J, Thorburn J. Extradural analgesia in labour: Complications of three techniques of administration. Br J Anaesth. 1994;73:619-623.

13. Kaynar AM, Shankar KB. Epidural infusion: Continuous or bolus? Anaesth Analg. 1999;89:534.

14. Curry PD, Pacsoo C, Heap DG. Patient-controlled epidural analgesia in obstetric anaesthetic practice. Pain. 1994;57:125-127.

15. Saito M, Okutomi T, Kanai Y, et al. Patientcontrolled epidural analgesia during labour using ropivacaine and fentanyl provides better maternal satisfaction with less local anesthetic requirement. J Anesth. 2005;19:208-212.

16. Smiley RM, Stephenson L. Patient-controlled epidural analgesia for labour. Int Anesthesiol Clin. 2007;45:83-98.

17. Vallejo M, Ramesh V, Phelps A, Sah N. Epidural labour analgesia: Continuous infusion versus patient-controlled epidural analgesia with background infusion versus without background infusion. The Journal of Pain 2007; 8:970-975.
18. Lim Y, Sia AT, Ocampo CE. Comparison of computer integrated patient controlled epidural analgesia vs. conventional patient controlled epidural analgesia for pain relief in labour. Anaesthesia. 2006;61:339-344.

19. Sia AT, Lim Y, Ocampo C. A comparison of a basal infusion with automated mandatory boluses in parturient-controlled epidural analgesia during labour. Anaesth Analg. 2007;104:673-678.

20. Lim Y, Sia ATH, Ocampo C. Automated regular boluses for epidural analgesia: A comparison with continuous infusion. Int $\mathrm{J}$ Obstet Anesth. 2005;4:305-309

21. Vella LM, Wellatts DG, Knott C, Lintin DJ, Justins DM, Reynolds F. Epidural fentanyl in labour - An evaluation of the systemic contribution to analgesia. Anaesthesia. 1985;40:741 --747.

22. Chua SM, Sia AT. Automated intermittent epidural boluses improve analgesia induced by intrathecal fentanyl during labour. Can J Anaesth. 2004;51:581-585.

23. Fettes PD, Moore CS, Whiteside JB, McLeod GA,etal. Intermittent vs. continuous administration of epidural ropivacaine with fentanyl for analgesia during labour. Br J Anaesth. 2006 ;97:359-64.

\title{
LECTURE DEMONSTRATION \& CERTIFICATION
}

\author{
ON

\section{Cardio Pulmonary Resuscitation}

$\begin{array}{ccc}\text { Venue } & \text { Trauma Lecture Hall } \\ \text { Date } & \text { National Hospital, Sri Lanka } \\ \text { Time } & \text { on Tuesdays } \\ & -\quad 9.00 \text { am } \\ \text { Conducted by } \\ \text { Dr Shirani Hapuarachchi } \\ \text { Consultant Anaesthetist, NSU } \\ \text { Contact } \\ \text { Ms Chamila Gamage, } \\ \text { Office Secretary, 2672327/2691111-Ext } 2571\end{array}$

